\title{
Intensi pembelian reusable bag. Peran social marketing untuk mencapai sustainable consumption
}

\author{
Ayu Ekasari \\ Fakultas Ekonomi dan Bisnis, \\ Universitas Trisakti, Jakarta, Indonesia \\ e-mail: ayu.ekasari@trisakti.ac.id
}

\begin{abstract}
Sustainable Development is one of the agenda many countries, including Indonesia, would like to achieve that should be approached by understanding consumption from individual perspective as a player. Marketing discipline can contribute through social marketing implementation by changing consumption pattern that leads to sustainable development. One of the sustainable consumption practices is using a reusable bag while shopping. Hopefully, this will eliminate negative impact of disposable plastic bag commonly used by consumer. A series of hypotheses were tested to find out whether consumers are willing to use reusable bag. The main variables that drive purchase intention are attitude, subjective norm, trust, perceived knowledge, and consumer innovativeness play significant role in forming positive consumers' attitude towards reusable bag and their purchase intention. However, there is no significant influence of revealed information on attitude towards reusable bag. Results of this research can help decision makers related to retailing or retailers themselves to design social marketing campaign and educate consumers about the benefits of reusable bag.
\end{abstract}

Key words: sustainable development, social marketing, sustainable consumption, reusable bag.

\begin{abstract}
Abstrak
Sustainable Development sebagai salah satu agenda yang ingin dicapai banyak Negara di dunia termasuk Indonesia selayaknya didekati juga dari aspek konsumsi di level paling bawah, yaitu menyangkut individu sebagai pelaku langsung.Disiplin ilmu pemasaran dapat berperan melalui pemasaran social (social marketing) agar terjadi perubahan pola perilaku konsumsi yang mengarah pada tercapainya sustainable development melalui sustainable consumption. Penggunaan kembali tas yang digunakan untuk berbelanja (reusable bag) adalah salah satu praktek sustainable consumption yang kini giat dikampanyekan di Indonesia untuk mengurangi dampak berbahaya limbah tas plastik yang dibuang begitu saja. Serangkaian hipotesis diuji untuk mengetahui sejauh mana intensi konsumen untuk membeli reusable bag.Variabel-variabel utama pembentuk intensi pembelian yaitu attitude, subjectivenorm, trust, perceived knowledge dan consumer innovativeness benar mendorong konsumen membeli reusable bag. Tingkat innovativeness seseorangpun serta pengetahuan yang dimilikinya juga menghasilkan sikap positif terhadap pembelian reusable bag.Namun, tidak ada pengaruh signifikan informasi (revealed information) di kemasan reusable bag terhadap peningkatan sikap positif konsumen.Hasil penelitian ini diharapkan dapat memberi masukan bagi pengambil kebijakan yang membawahi usaha eceran serta pengecer pada khususnya untuk mengedukasi konsumen tentang manfaat reusable bag melalui kampanye social marketing yang terarah.
\end{abstract}

Kata kunci:sustainable development, social marketing, sustainable consumption, reusable bag.

JEL: M30, M31, M37, M39 DOI: 10.20885/jsb.vol21.iss2.art2

\section{Pendahuluan}

Cepatnya pertumbuhan ekonomi di tiga dekade terakhir abad 20 ini telah mendorong konsumsi dan eksploitasi sumber daya alam yang berlebihan. Dampak yang kini dirasakan adalah kerusakan lingkungan, seperti meningkatnya gas rumah kaca, menipisnya lapizan ozon di atmosfer, sumber daya tanah dan air yang tercemar serta rusaknya ekosistem. Hal-hal tersebut menyadarkan akademisi, 
pecinta lingkungan maupun pemerintah untuk menjaga keseimbangan alam dengan berproduksi dan berkonsumsi yang sehat.

Di tingkat global, banyak negara dan perusahaan besar di dunia mulai peduli pada konsep keberkelanjutan (sustainability) dan menjadikannya sebagai agenda besar untuk dilaksanakan, seperti tertuang dalam Earth Summit di Rio de Janeiro tahun 1992 ((Peattie dan Crane, 2005; Schaefer dan Crane, 2005).

PBB membentuk organisasi independen pada tahun 1983, World Commision on Environment and Development yang ditugasi mengidentifikasi masalah pembangunan dan ekonomi serta mencari solusinya. Badan ini juga dikenal dengan nama Brundtland Commision, diambil dari nama pimpinannya, Gro Harlem Brundtland, yang merupakan perdana menteri Norwegia. Salah satu anggota komisi adalah Emil Salim, mantan Menteri Kependudukan dan Lingkungan Hidup Republik Indonesia.

Pada tahun 1987, Brundtland Commision menerbitkan sebuah laporan berjudul "Our Common Future" yang merupakan respons atas konflik yang muncul antara mempercepat pertumbuhan ekonomi dengan degradasi lingkungan di skala global.Dalam laporan tersebut, dicetuskan konsep sustainable developmentyang menitikberatkan pada keadilan antar generasi, yang berarti pemenuhan kebutuhan masa kini tidak boleh mengorbankan generasi mendatang untuk memenuhi kebutuhan mereka. Menurut laporan tersebut, antara lingkungan dan pembangunan tidak bisa dipisahkan. (http://www.hks.harvard.edu.)

Di ranah akademi, Brundtland Report memunculkan perdebatan yang menarik,apakah pemasaran berperan dalam memicu perningkatan konsumsi atau bisa memberi kontribusi terhadap pemecahan masalah lingkungan (Peattie dan Peattie, 2008). Bahkan pemasaran sering disebut antithesis dari keberlanjutan, karena pemasaran mendorong orang melakukan konsumsi, sedangkan keberlanjutan justru mendorong orang untuk memenuhi kebutuhan mereka (konsumsi) tanpa mengorbankan kepentingan generasi mendatang (Jones et.al, 2008; Her Majesty's Government, 2005).

Dari telaah para akademisi, pemasaran juga dapat berperan dalam mencapai sustainable development melalui sustainable consumption yaitu merubah perilaku individu di level individu agar mengarah pada keberlanjutan, seperti melakukan daur ulang, mengonsumsi makanan organik, maupun menjalankan pola hidup sehat serta berkonsumsi yang bisa melestarikan lingkungan demi generasi mendatang. Untuk mewujudkan sustainable consumption, diperlukan kesadaran individu untuk merubah pola konsumsinya agar mempertahankan kelestarian lingkungan.

Melihat kritik terhadap pemasaran di atas, muncul pemikiran untuk memanfaatkan socialmarketing agar perilaku individu dapat diubah menuju gaya hidup berkelanjutan yang tidak merugikan lingkungan alam (Peattie dan Peattie, 2008). Sesuai perkembangannya sejak diperkenalkan oleh Kotler dan Zaltman (1971) hingga saat ini, makna social marketing tidak mengalami perubahan. Social marketing bisa diartikan sebagai penggunaan teknik-teknik pemasaran agar target audience secara sukarela bersedia menerima, menolak, mengabaikan dan memodifikasi suatu perilaku untuk mencapai manfaat bagi individu, kelompok maupun masyarakat (Andreassen, 1995). Social marketing bisa dipraktekkan oleh berbagai pihak, antara lain pemerintah, lembaga non profit maupun perusahaan manufakturing/jasa.

Salah satu perilaku peduli lingkungan yang diharapkan dapat meminimalisir pencemaran tanah dan merupakan bagian dari sustainable consumption adalah menggunakan tas belanja yang dapat dipakai kembali (reusable bag) yang bukan berupa tas plastik .Dalam penelitiannya, Johyung dan Ha (2012) menyatakan bahwa perilaku peduli lingkungan bisa dilakukan di tingkat privat, baik individu maupun rumah tangga, salah satunya adalah menggunakan barang yang ramah lingkungan. Sebagaimana diketahui, plastik yang banyak dipakai untuk menempatkan belanjaan konsumen adalah zat kimia yang membutuhkan waktu seratus tahun untuk terurai di dalam tanah. Hal ini mengakibatkan sumber bahan makanan manusia yang berasal dari tanah akan teracuni apabila tas plastik dibuang begitu saja. Penggunaan tas plastik paling banyak terjadi di perdagangan eceran (retailing). 
Akhir-akhir ini retailers sudah menyadari dampak berbahaya tas plastik sehingga mereka mulai menjual tas belanja yang dapat digunakan kembali (reusable bag), bukan sekedar tas plastik yang diklaim bisa didaur ulang dan cepat terurai. Fenomena baru ini cukup menggembirakan, karena retailer bisa dikatakan telah menerapkan social marketing, yaitu mengajak konsumen merubah perilakunya dengan menggunakan reusable bag untuk berbelanja.

Di dalam Undang Undang Nomer 18/2008 yang mengatur tentang pengelolaan sampah juga disebutkan agar pelaku bisnis membatasi penggunaan kantong plastik dan mendorong konsumennya untuk mengurangi penggunaan kantong plastik saat berbelanja.Pada tahun 2016, Direktorat Pengelolaan Sampah - Kementerian Lingkungan Hidup dan Kehutanan berencana mewujudkan kebijakan kantong plastik berbayar dalam rangka mencapai Indonesia Bersih Sampah 2020. Survey pun sudah mulai diluncurkan untuk menggali sejauh mana kebijakan ini akan didukung oleh masyarakat luas.

Keseriuan Pemerintah untuk mengurangi limbah plastik khususnya dan membebaskan Indonesia dari sampah umumnya benar-benar dilaksanakan melalui Hari Peduli Sampah Nasional pada 21 Februari 2016 yang berisi deklarasi Indonesia Bebas Sampah 2020, pencanangan uji coba kantong plastik berbayar dan pembagian reusable bag yang diselenggarakan di Bunderan HI Jakarta. Uji coba kantong plastik berbayar mendapat dukungan dari Asosiasi Pengusaha Ritel Indonesia (APRINDO) dan telah diujicobakan di 17 kota. Namun setelah kampanye kantong plastik berbayar berakhir, patut dipertanyakan bagaimana intensi masyarakat: apakah kembali menggunakan kantong plastik atau membeli reusable bag untuk digunakan terus menerus. Sebagai catatan, kantong plastik berbayar dihargai Rp.200,- saat gerakan uji coba, sedangkan reusable bag yang dijual retailer besar berharga sekitar Rp. 10.000,- hingga Rp. 20.000,-.

Oleh karena reusable bag adalah sesuatu yang baru, tentu diperlukan kampanye social marketing untuk mendorong konsumen mau menggunakannya. Pemasar, dalam hal ini retailer, harus mengetahui terlebih dahulu faktor-faktor yang bisa mempengaruhi intensi konsumen untuk merubah perilakunya, yaitu menggunakan tas yang sama dan dapat digunakan kembali (reusable bag) saat berbelanja. Untuk itu diperlukan sikap (attitude) positif konsumen bahwa reusable bag benar-benar lebih baik dan bermanfaat dibanding tas plastik.

Penelitian-penelitian terbaru mengindikasikan bahwa berperilaku peduli lingkungan yang mengarah pada sustainable consumption banyak dipengaruhi oleh aspek psikologis yang ada dalam diri manusia (Johyung dan Ha, 2012; Lao, 2014; Chih dan Yu, 2015), antara lain consumer innovativeness, attitude, subjective norm yang semuanya mengarah pada intensi melakukan perilaku peduli lingkungan.

Beberapa peneliti menemukan bahwa untuk membangun sikap (attitude) positif konsumen dalam perilaku peduli lingkungan, perlu adanya kepercayaan (trust), revealed information serta perceived knowledge yang ada dalam diri konsumen tentang perilaku peduli lingkungan yang dikampanyekan (O'Fallon, 2007; Kim, Ferrin dan Rao, 2008; Gracia dan Margitris, 2008; Chih dan $\mathrm{Yu}, 2015)$. Seberapa paham seseorang akan informasi yang terkandung dalam perilaku peduli lingkungan (misalnya kemasan) serta pengetahuan yang dimiliki seseorang juga mempengaruhi sikap dan intensinya berperilaku peduli lingkungan.

Disamping itu, aspek psikologis lain yang juga bisa digunakan untuk memahami perilaku peduli lingkungan adalah consumer innovativeness yang menjelaskan sejauh mana tingkat penerimaan seseorang terhadap sesuatu yang baru mendahului orang lain disekitarnya (Rogers dalam Schiffman dan Kanuk, 2010). Beberapa peneliti sebelumnya menemukan bahwa consumer innovativeness mempunyai pengaruh terhadap keinginan seseorang untuk pembelian produk baru (Chen, 2011 dan Im et al., 2003). Demikian pula perilaku konsumen yang tergolong baru yaitu online shopping dan cyber bank juga didorong oleh consumer innovativeness di dalam diri mereka (Lassar, Manolis dan Lassar, 2005 dan Chang dan Zhu, 2007). Lao (2014) juga mengemukakan bahwa terkait produk hijau yang adakalanya menggunakan teknologi baru atau menyediakan fungsi kegunaan baru yang inovatif, maka konsumen dengan derajat innovativeness tinggi cenderung bersedia melakukan pembelian produk hijau. 
Secara psikologis terbukti bahwa pengaruh luar yang bisa berasal dari keluarga maupun teman (subjective norm) juga mendorong seseorang untuk menerima inovasi dalam perilaku peduli lingkungan seperti membeli makanan organik serta produk ramah lingkungan dan membuatnya berniat membeli (purchase intention) produk organik tersebut (Kalafatis dan Pollard, 1999; Luo, 2010; Kim dan Chung, 2011; Lao, 2014).

Di sisi lain penelitian tentang perilaku peduli lingkungan, sikap (attitude) ternyata juga dibentuk oleh tersedianya informasi (revealed information) dan perceived knowledge serta kepercayaan (trust)terhadap perilaku peduli lingkungan (Chih dan Yu, 2015; Janssen dan Hamm, 2012; Vermeir dan Verbeke, 2006; Zakowska-Biemans, 2011). Para peneliti tersebut menemukan bahwa makin mudahnya konsumen memahami informasi serta mempunyai pengetahuan memadai serta percaya terhadap suatu perilaku peduli lingkungan yang dikampanyekan, akan meningkatkan kemauan mereka untuk melakukannya.

Kebaruan penelitian ini adalah menambah variabel consumer innovativeness untuk melengkapi model sebelumnya dari Chih dan Yu (2015) dan Lao (2014) dalam memprediksi perilaku peduli lingkungan yang belum diteliti, yaitu penggunaan reusable bag.

\section{Review Literatur dan Hipotesis}

Sikap (attitude) adalah komponen penting dalam Theory-of- Reasoned Action (Ajzen, 1991) yang sudah kokoh dan banyak dipakai untuk memahami perilaku konsumen dan merupakan predictonuntuk purchase intention dalam TRA. Penelitian tentang perilaku peduli lingkungan banyak menggunakan TRA dan terbukti bahwa makin positif sikap seseorang terhadap perilaku peduli lingkungan, maka ia berniat melaksanakannya (Magnuson et al., 2003; Johyung dan Ha, 2012; Padel dan Foster, 2005; Honkanen et.al, 2006; Chih dan Yu, 2015; Lao, 2014).

Subjective norm juga merupakan komponen TRA yang menggambarkan pengaruh dan tekanan sosial dari luar agar seseorang melakukan suatu tindakan (Ajzen, 1991) dan banyak dipakai untuk memahami perilaku peduli lingkungan. Ajzen (1991) menyatakan bahwa subjective norm ditentukan oleh harapan orang lain bahwa seseorang sebaiknya mengikuti norma-norma yang berlaku di masyarakat. Dalam hal penggunaan reusable bag, tekanan sosial ini bisa berupa pendapat orang, berita dari media, kampanye sosial dari pemerintah dan lembaga non-profit. Adapun norma yang berlaku dan trend yang berlaku saat ini adalah sebaiknya orang melakukan konsumsi secara berkelanjutan, salah satunya adalah tidak mencemari lingkungan. Beberapa penelitian telah membuktikan pengaruh positif subjective norm terhadap intensi melakukan perilaku peduli lingkungan (Chen, 2007; Dean et al., 2008; Chih danYu, 2015).

$\mathrm{H} 1$ : Attitude pada reusable bag berpengaruh positif terhadappurchase intention

$\mathrm{H} 2$ : Subjective norm tentang reusable bag berpengaruh positif terhadap purchase intention

Morgan dan Hunt (1994) menyatakan bahwa kepercayaan (trust) akan muncul jika salah satu pihak yakin akan integritas pihak lain yang menjadi partner dalam pertukaran. Selanjutnya trust juga menjadi faktor penentu timbulnya sikap positif dan intensi pembelian dalam konteks pemasaran (Garbarino dan Johnson, 1999; Wu dan Chen, 2005; Gifford dan Bernard, 2006). Salah satu perilaku yang sustainable adalah konsumsi makanan organik, dan beberapa penelitian membuktikan bahwa makin percaya orang terhadap manfaat makanan organik akan mendorong mereka bersikap positif dan bersedia membelinya (Wu dan Chen, 2005; Jannsen dan Hamm, 2012; Chih dan Yu, 2015).

H3: Trust berpengaruh positif terhadap attitude pada reusable bag

H4: Trust berpengaruh positif terhadap purchase intention

Di sisi lain, informasi yang jelas adalah sangat penting bagi konsumen dalam pengambilan keputusan pembelian. Terlebih dalam memutuskan untuk menjalankan perilaku yang sustainable, misalnya membeli makanan organik, dibutuhkan informasi jelas dan kredibel sehingga tercipta trust dan attitude positif tentang makanan organic (Gracia dan Margitris, 2008). Khusus untuk makanan 
organik, logo dan pelabelan berperan penting dalam menyampaikan informasi kepada konsumen karena dapat meningkatkan sikap positif dan intensi pembelian (Zakowska-Biemans, 2011) serta membantu konsumen berpikir rasional terkait makanan organic (O'Fallon et al., 2007). Oleh karena penggunaan reusable bag merupakan salah satu jenis sustainable consumption juga, sama dengan konsumsi makanan organik, maka logo dan label yang memberi informasi tentang reusable bag juga diduga dapat meningkatkan sikap positif dan kepercayaan terhadap tas tersebut.

H5: Revealed information berpengaruh positif terhadap trust pada reusable bag

H6: Revealed information berpengaruh positif terhadap attitude pada reusable bag

Pengetahuan yang dimiliki konsumen terkait suatu perilaku konsumsi dapat mempengaruhi sikap dan kepercayaan untuk melaksanakan perilaku tersebut.Beberapa penelitian terkait salah satu perilaku sustainable, yaitu konsumsi makanan organik, membuktikan bahwa pengetahuan konsumen tentang manfaat makanan organik meningkatkan sikap positif mereka terhadap makanan organik (Gifford dan Bernard, 2006; Padel dan Foster, 2005). Terlebih lagi, makanan organik adalah sesuatu yang baru bagi konsumen, sehingga pengetahuan yang memadai tentang makanan organik, dapat meningkatkan kepercayaan mereka yang pada akhirnya mendorong mereka untuk membelinya (Vermeir dan Verbeke, 2006; Hughner et al., 2007, O'Fallon et al., 2007; Gracia dan Margitris, 2008).

Analog dengan pembahasan tentang makanan organik, konsumen perlu mempunyai pengetahuan yang cukup tentang mengapa mereka sebaiknya menggunakan reusable bag agar timbul kepercayaan dan sikap positif terhadap reusable bag.

H7: Perceived knowledge berpengaruh positif terhadap trust pada reusable bag

H8: Perceived knowledge berpengaruh positif terhadap attitude pada reusable bag

Sebagai salah satu karakter dalam kepribadian, innovativeness menggambarkan derajat penerimaan seseorang akan sesuatu yang baru dan bisa dijadikan faktor untuk dieksploitir pemasar dalam mengampanyekan inovasi nya kepada konsumen (Schifman dan Kanuk, 2011). Dalam konteks pemasaran, berbagai perilaku peduli lingkungan perlu dikampanyekan dan dengan memahami innovativeness yang ada dalam diri konsumen, pemasar bisa menerapkan strategi pemasaran yang tepat dengan menonjolkan innovativeness tersebut. Im et.al (2008), Bartels dan Reinders (2010), Chang dan Zu (2007) dan Lao (2014) menemukan bahwa consumer innovativeness mendorong konsumen bersikap positif dan berniat membeli makanan organik serta pendingin ruangan hemat energi, dua diantara berbagai perilaku peduli lingkungan yang merupakan inovasi produsennya.

Jika seseorang mempunyai sisi innovativeness tinggi dalam dirinya, ia cenderung bersedia menerima norma dan pengaruh yang berasal dari lingkungan eksternalnya. Diduga individu yang bersedia menerima hal-hal baru akan lebih toleran dan modern dalam menghadapi tekanan dari pihak lain untuk menerima suatu perilaku yang baru (Lao, 2014).

H9 : Consumer innovativeness berpengaruh positif terhadap attitude pada reusable bag

$\mathrm{H} 10$ : Consumer innovativeness berpengaruh positif terhadap subjective norm

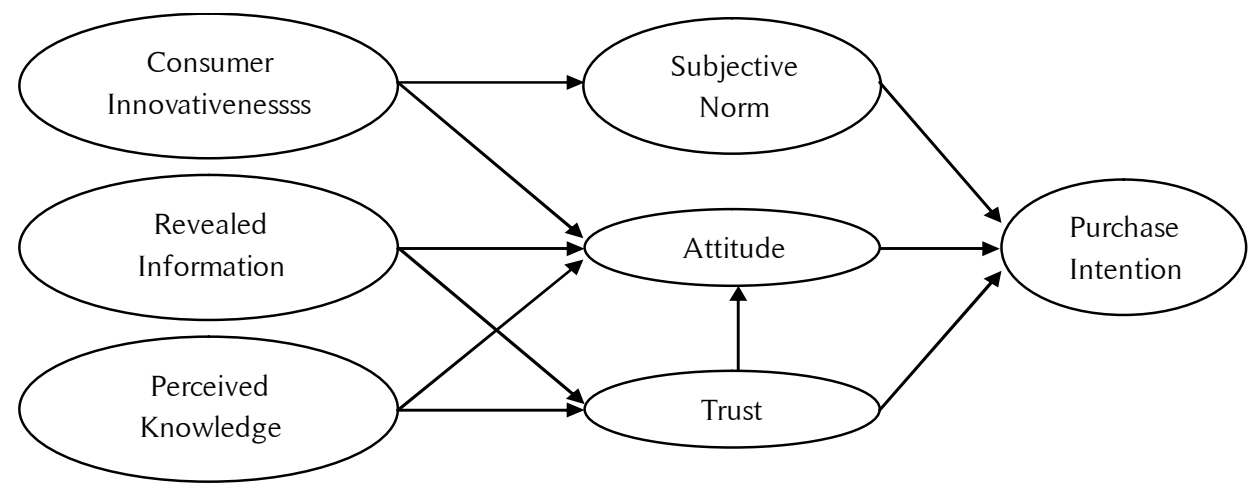

Gambar 1.Rerangka Konseptual 


\section{Metode Penelitian}

Rancangan penelitian ini berupa uji hipotesis dan dilakukan secara cross-sectional serta menggunakan konsumen individu sebagai unit analisis, yaitu 150 orang individu yang mengunjungi supermarket Carrefour, Hero dan Superindo minimal tiga kali dalam enam bulan terakhir ini. Construct Attitude, Subjective Norm, Trust, Revealed Information, Perceived Knowledge dan Purchase Intention berikut instrument-instrumennya diadopsi dari Chih dan Yu (2015), sedangkan construct Consumer Innovativeness dan intrumen-instrumennya menggunakan pengukuran dari Lao (2014). Kesemua instrument diukur menggunakan skala Likert satu sampai lima, dimulai dari sangat tidak setuju (1) hingga 5 (sangat setuju).

Dari loading factor, dapat dilihat bahwa semua instrument lebih besar daripada 0.4, sehingga memenuhi persyaratan seperti dikemukakan Hair et.al (2006). Demikian pula semua construct mempunyai koefisien Cronbach Alpha di atas 0.6 seperti disyaratkan oleh Sekaran dan Bougie (2013). Analisis data dilakukan menggunakan software AMOS versi 19.1.

Table 1. Hasil Uji Validitas and Reliabilitas

\begin{tabular}{|c|c|c|}
\hline Variable & $\begin{array}{l}\text { Loading } \\
\text { Factor }\end{array}$ & $\begin{array}{c}\text { Reliability } \\
\text { (Cronbach Alpha) }\end{array}$ \\
\hline Revealed Information & & 0,8746 \\
\hline $\begin{array}{l}\text { 1. Menurut saya, label Reusable Bag (gambar daun, simbol daur ulang ) memberikan } \\
\text { informasi yang benar tentang Reusable Bag }\end{array}$ & 0,784 & \\
\hline $\begin{array}{l}\text { 2. Menurut saya, label Reusable Bag (gambar daun, simbol daur ulang) memberikan } \\
\text { informasi yang akurat tentang Reusable Bag }\end{array}$ & 0,872 & \\
\hline $\begin{array}{l}\text { 3. Menurut saya, label Reusable Bag (gambar daun, simbol daur ulang) memberikan } \\
\text { informasi yang memadai tentang Reusable Bag }\end{array}$ & 0,872 & \\
\hline $\begin{array}{l}\text { 4. Saya puas dengan informasi yang disediakan pada label Reusable Bag (gambar daun, } \\
\text { simbol daur ulang) }\end{array}$ & 0,784 & \\
\hline Perceived Knowledge & & 0,7615 \\
\hline 1. Saya memiliki banyak pengetahuan tentang Reusable Bag & 0,682 & \\
\hline $\begin{array}{l}\text { 2. Menurut pendapat saya, rata-rata orang Indonesia memiliki banyak pengetahuan } \\
\text { tentang Reusable Bag }\end{array}$ & 0,551 & \\
\hline $\begin{array}{l}\text { 3. Menurut pendapat saya, pemerintah memiliki banyak pengetahuan tentang Reusable } \\
\text { Bag }\end{array}$ & 0,641 & \\
\hline $\begin{array}{l}\text { 4. Menurut pendapat saya, ilmu pengetahuan juga menyediakan banyak pengetahuan } \\
\text { tentang Reusable Bag. }\end{array}$ & 0,604 & \\
\hline $\begin{array}{l}\text { 5. Menurut pendapat saya, industri retailer/eceran (Supermarket dan Hypermarket) juga } \\
\text { menyediakan banyak pengetahuan tentang Reusable Bag. }\end{array}$ & 0,655 & \\
\hline \multicolumn{3}{|l|}{ Subjective Norm } \\
\hline 1. Menurut saya, keluarga saya berfikir saya sebaiknya membeli Reusable Bag. & 0,711 & \\
\hline 2. Menurut saya, teman-teman saya berfikir saya sebaiknya membeli Reusable Bag. & 0,769 & \\
\hline $\begin{array}{l}\text { 3. Menurut saya, berita dan majalah mempengaruhi keputusan saya membeli Reusable } \\
\text { Bag. }\end{array}$ & 0,734 & \\
\hline $\begin{array}{l}\text { 4. Menurut saya, dukungan pemerintah terhadap Reusable Bag mempengaruhi } \\
\text { keputusan saya membeli Reusable Bag. }\end{array}$ & 0,652 & \\
\hline \multicolumn{2}{|l|}{ Attitudes } & 0,7911 \\
\hline $\begin{array}{l}\text { 1. Menurut saya, Reusable Bag mengandung lebih sedikit bahan kimia di bandingkan } \\
\text { tas plastik }\end{array}$ & 0,478 & \\
\hline 2. Menurut saya, Reusable Bag lebih aman untuk digunakan dibandingkan tas plastik. & 0,776 & \\
\hline Menurut saya, Reusable Bag lebih sehat untuk digunakan dibandingkan tas plastik. & 0,805 & \\
\hline Menurut saya, Reusable Bag lebih nyaman digunakan dibandingkan tas plastik. & 0,637 & \\
\hline Menurut saya, Reusable Bag memiliki kualitas lebih unggul dibandingkan tas plastik. & 0,720 & \\
\hline 6. Menurut saya, harga Reusable Bag lebih mahal dibandingkan tas plastik. & 0,455 & \\
\hline $\begin{array}{l}\text { 7. Menurut saya, Reusable Bag lebih menarik untuk digunakan dibandingkan tas } \\
\text { plastik. }\end{array}$ & 0,498 & \\
\hline \multicolumn{2}{|l|}{ Trust } & 0,8210 \\
\hline $\begin{array}{l}\text { 1. Saya berfikir retailer/eceran(Supermarket dan Hypermarket) menyadari tanggung } \\
\text { jawab mereka (tentang menyediakan Reusable Bag) }\end{array}$ & 0,633 & \\
\hline
\end{tabular}




\begin{tabular}{|c|c|c|}
\hline Variable & $\begin{array}{l}\text { Loading } \\
\text { Factor }\end{array}$ & $\begin{array}{c}\text { Reliability } \\
\text { (Cronbach Alpha) }\end{array}$ \\
\hline $\begin{array}{l}\text { 2. Saya percaya retailer/eceran (Supermarket dan Hypermarket) yang menjual Reusable } \\
\text { Bag benar-benar menjual tas yang berkualitas }\end{array}$ & 0,753 & \\
\hline 3. Saya percaya pada label yang tertera di Reusable Bag (gambar daun, simbol daur ulang ) & 0,833 & \\
\hline 4. Saya percaya kepada retailer/eceran yang menjual Reusable Bag. & 0,681 & \\
\hline Purchase Intention & & 0,8692 \\
\hline $\begin{array}{l}\text { 1. Jika Reusable Bag tersedia di retailer/eceran (Supermarket dan Hypermarket, saya } \\
\text { akan membelinya. }\end{array}$ & 0,784 & \\
\hline 2. Saya bersedia untuk membeli Reusable Bag meskipun harganya mahal. & 0,853 & \\
\hline 3. Kemungkinan saya membeli Reusable Bag sangat tinggi. & 0,840 & \\
\hline Consumer Innovativeness & & 0,8043 \\
\hline 1. Saya suka menggunakan produk dengan desain dan fungsi yang baru. & 0,722 & \\
\hline 2. Saya suka membaca berbagai informasi dan berita baru tentang produk baru & 0,706 & \\
\hline 3. Saya suka mempelajari dan menguasai perubahan dan karakteristik dari produk baru & 0,779 & \\
\hline
\end{tabular}

Tabel 2.Hasil Uji Kesesuaian Model(Goodness-of-fit)

\begin{tabular}{|c|c|c|c|c|}
\hline Jenis Pengukuran & $\begin{array}{l}\text { Goodness of } \\
\text { Fit Index }\end{array}$ & Nilai & Cut-Off & Kesimpulan \\
\hline $\begin{array}{c}\text { Absolute Fit Measures } \\
\rho \text {-value }\end{array}$ & Chi square & $\begin{array}{c}834.02 \\
0.000\end{array}$ & $\begin{array}{l}\text { Diharapkan dalam nilai kecil } \\
\qquad \geq 0.05\end{array}$ & $\begin{array}{l}\text { Tidak goodness-of-fit } \\
\text { Tidak goodness-of-fit }\end{array}$ \\
\hline Normed chi-square & CMIN/DF & 2.129 & Batas bawah 1 , batas atas 5 & Goodness-of-fit \\
\hline $\begin{array}{c}\text { RMSEA } \\
\text { Incremental Fit Measures }\end{array}$ & & 0.087 & $\leq 0.10$ & Goodness-of-fit \\
\hline NFI & & 0.717 & $\geq 0.90$ & Marginal fit \\
\hline CFI & & 0.824 & $\geq 0.90$ & Marginal fit \\
\hline
\end{tabular}

Sumber: Data diolah

Dari tabel 5 dapat dilihat bahwa walaupun ada dua kriteria goodness-of-fit yang tidak tercapai, namun model penelitian bisa diterima, karena ada beberapa kriteria yang mencapai goodness-of-fit maupun marginal fit.

\section{Hasil dan Pembahasan}

Adanya pengaruh positif sikap (attitude) dan subjective norm terhadap intensi membeli reusable bag membuktikan Theory-of-Reasoned Action yang dikemukakan oleh Ajzen (1991) dan beberapa penelitian sebelumnya terkait perilaku peduli lingkungan (Magnuson et.al, 2003; Park dan Ha, 2012; Padel dan Foster, 2005; Honkanen et.al, 2006; Chih dan Yu, 2015; Lao, 2013; Chen, 2007; Dean et al., 2008). Hal ini memperlihatkan bahwa jika seseorang merasa reusable bag aman lebih aman, mengandung lebih sedikit bahan kimia, lebih sehat, lebih menarik dan nyaman untuk digunakan, maka ia terdorong untuk membeli dan menggunakannya untuk berbelanja.

Adanya pengaruh positif kepercayaan (trust) terhadap sikap (attitude) pada reusable bag dan intensi membelinya juga menguatkan penelitian sebelumnya dalam konteks perilaku peduli lingkungan (Wu dan Chen, 2005; Jannsen dan Hamm, 2012; Chih dan Yu, 2015).Pembuktian kedua hipotesis ini menunjukkan kepercayaan konsumen terutama terhadap retailer/pengecer/supermarket yang menjual reusable bag sehingga mereka berniat membeli dan menggunakannya.

Yang menarik adalah walaupun informasi yang tertera pada reusable bag (revealed information) meningkatkan kepercayaan konsumen, namun tidak berpengaruh positif secara langsung terhadap sikap akanreusable bag. Kedua hasil ini selain mendukung juga bertentangan dengan penelitian Chih dan Yu (2015) yang menyatakan revealed information berpengaruh positif terhadap sikap dan kepercayaan pada perilaku peduli lingkungan.

Diduga walaupun informasi yang tertera pada reusable bag berupa gambar daun dan symbol daur ulang baru cukup membuat konsumen mempercayai bahwa supermarket tempat mereka berbelanja 
sudah bertanggung jawab akan perlunya menjaga kelestarian lingkungan, namun tidak cukup kuat membentuk sikap positif mereka terhadap reusable bag. Informasi yang tertera di tas belum bisa membuat konsumen yakin bahwa tas tersebut benar-benar lebih nyaman, sehat, aman, tidak mengandung bahan kimia serta nyaman digunakan. Keterangan yang ada di tas juga tidak memberi informasi tentang manfaat reusable bag, sehingga konsumen tidak merasa perlu membelinya. Selain itu, terdapat kemungkinan bahwa untuk meningkatkan sikap positif diperlukan terlebih dahulu kepercayaan sebagai variabel intervening seperti dikemukakan oleh Janssen dan Hamm, 2012; Vermeir dan Verbeke, 2006; Zakowska-Biemans, 2011). Dengan demikian seperti pembuktian penelitian-penelitian lalu, informasi yang tertera dalam reusable bag adalah predictor kuat untuk menimbulkan kepercayaan yang pada akhirnya akan meningkatkan sikap positif dan niat membelinya.

Di sisi lain, pengetahuan yang dimiliki konsumen tentang reusable bag ternyata bisa memberi pengaruh positif terhadap sikap dan kepercayaan terhadap reusable bag seperti telah dibuktikan oleh beberapa peneliti sebelumnya (Vermeir dan Verbeke, 2006;Hughner etal., 2007, O'Fallon et al., 2007; Gracia dan Margitris, 2008). Hasil ini memperlihatkan bahwa konsumen sudah mempunyai pengetahuan cukup tentang reusable bag, disamping mereka juga mengetahui bahwa pemerintah dan pengecer/retailer sudah memberikan pengetahuan yang memadai tentang manfaat reusable bag.

Tingkat innovativeness konsumen ternyata terbukti meningkatkan sikap positif mereka terhadap penggunaan reusable bag dan intensi untuk membelinya seperti dibuktikan oleh Lao (2014) tentang pengaruh consumer innovativeness terhadap sikap dan intensi melakukan perilaku peduli lingkungan. Mereka yang suka menggunakan produk dengan disain dan fungsi baru, gemar membaca informasi tentang produk baru serta suka mempelajari perubahan dan karakteristik produk baru, cenderung menganggap reusable bag memang lebih aman, sehat dan berkualitas serta bersedia membelinya.

Rangkuman hasil uji hipotesis dapat dilihat di tabel 3 berikut:

Tabel 3.Hasil Uji Hipotesis

\begin{tabular}{lccc}
\hline \multicolumn{1}{c}{ Hipotesis } & Coeffiecient & $p$-value & Keputusan \\
\hline H1 : Attitudes $\rightarrow$ Purchase Intention & 0,338 & 0,026 & H1: Didukung \\
H2 $:$ Subjective Norm $\rightarrow$ Purchase Intention & 0,568 & 0,000 & H2 : Didukung \\
H3 : Trust $\rightarrow$ Attitudes & 0,736 & 0,003 & H3: Didukung \\
H4: Trust $\rightarrow$ Purchase Intention & 0,810 & 0,000 & H4 : Didukung \\
H5 : Revealed Information $\rightarrow$ Trust & 0,171 & 0,008 & H5 : Didukung \\
H6: Revealed Information $\rightarrow$ Attitude & 0,067 & 0,207 & H6: Tidak didukung \\
H7 : Perceived Knowledge $\rightarrow$ Attitudes & 0,467 & 0,018 & H7: Didukung \\
H8 : Perceived Knowledge $\rightarrow$ Trust & 0,625 & 0,000 & H8 : Didukung \\
H9: Consumer Innovativeness $\rightarrow$ Subjective Norm & 0,892 & 0,000 & H9: Didukung \\
H10: Consumer Innovativeness $\rightarrow$ Attitudes & 0,311 & 0,009 & H10: Didukung \\
\hline
\end{tabular}

Sumber: Data diolah

\section{Kesimpulan}

Penelitian ini merupakan pionir dalam memahami perilaku peduli lingkungan terkait penggunaan tas untuk berbelanja yang bukan terbuat dari plastik. Dengan menggunakan model penelitian yang menggabungkan beberapa variabel, penelitian ini mencoba menjelaskan faktor-faktor yang mendorong sikap positif dan intensi pembelian reusable bag, salah satu perilaku peduli lingkungan yang amat jarang diteliti. Oleh karena masyarakat Indonesia masih terbiasa menggunakan tas plastik saat berbelanja, beberapa saran bisa dilaksanakan oleh retailer dalam mengembangkan kampanye social marketing untuk merubah perilaku konsumen.

Pertama, diperlukan informasi yang memadai di kemasan tas untuk mendorong konsumen mempercayainya dan bersikap positif akan pemakaian reusable bag. Saat ini beberapa reusable bag sudah menyantumkan simbol daur ulang dan kalimat tentang penyelamatan lingkungan, antara lain: 
"selamatkan lingkungan untuk hari esok yang lebih baik", "sahabat lingkungan", "lindungi lingkungan kita", "reduce, reuse, go green". Namun kalimat-kalimat tersebut masih terlalu abstrak dan normatif, sehingga perlu penjelasan lebih konkrit. Sebaiknya ditambahkan kaitan penggunaan reusable bag dengan penyelamatan lingkungan serta bahaya tas plastik bagi lingkungan terutama tanah. Kalimatkalimat tersebut bisa dibuat dengan ringkas, padat dan diletakkan secara proporsional, misalnya: "hindari tas plastik sekali pakai yang bisa mencemari tanah, gunakan tas yang bisa digunakan kembali". Oleh karena tidak ada pengaruh positif revealed information terhadap attitude, maka diperlukan informasi yang tepat dan konkrit untuk membangun kepercayaan konsumen terlebih dahulu.

Kedua, retailer juga dapat meningkatkan pengetahuan konsumen melalui komunikasi pemasaran, yaitu banner yang terpasang di beberapa tempat di dalam supermarket terutama di pintu masuk dan tempat pembayaran, serta penempelan tulisan di sudut-sudut tertentu yang strategis agar konsumen mudah membacanya. Selain itu, dalam pencetakan brosur/flyer yang sering dilakukan retailer saat ada promosi, juga dicantumkan pengetahuan tentang manfaat menggunakan reusable bag.Retailer juga perlu mengadakan kampanye khusus dengan memberi reward berupa hadiah atau potongan harga bagi konsumen yang berbelanja menggunakan reusable bag. Untuk mengomunikasikan manfaat reusable bag dapat juga dilakukan melalui website perusahaan, dengan menampilkan foto tas yang dijual serta pengetahuan terkait bahaya menggunakan tas plastik bagi lingkungan. Demikian pula, kasir yang melayani konsumen dilatih agar menawarkan reusable bag kepada konsumen dan secara singkat menjelaskan manfaatnya saat sedang melayani konsumen, disamping reusable bag itu sendiri diletakkan di dekat kasir untuk memudahkan konsumen melihatnya.

Ketiga, seiring temuan penelitian bahwa ciri kepribadian innovativeness terbukti berpengaruh positif terhadap attitude dan subjective norm, maka dalam kampanye sosial juga perlu dicantumkan bahwa mereka yang menggunakan reusable bag adalah innovator. Diharapkan, hal ini dapat meningkatkan kepercayaan diri dan kebanggaan mereka yang menggunakan reusable bag. Retailer juga harus merancang reusable bag secara inovatif, seperti tas yang bisa dilipat kecil serta menggunakan bahan baku yang berasal dari bahan daur ulang. Dalam kampanyenya, retailer sebaiknya menyampaikan bahwa dengan menggunakan reusable bag sebagai salah satu inovasi perilaku peduli lingkungan, maka dampak positifnya akan dirasakan oleh masyarakat luas,termasuk orang-orang dekat konsumen, seperti keluarga dan teman, yaitu tanah tidak tercemar oleh tas plastik sekali pakai yang langsung dibuang.

Keempat, penelitian membuktikan bahwa subjective norm berpengaruh positif terhadap intensi membeli reusable bag, serta adanya pengaruh positif innovativeness terhadap subjective norm. Dalam kampanye social marketing melalui website maupun youtube, retailer dapat memperlihatkan kerabat, teman dan orang di sekitar konsumen ikut mendorongnya menggunakan reusable bag. Jika konsumen percaya bahwa orang-orang dekat mereka berpikir bahwa menggunakan reusable bag adalah bermanfaat, retailer dapat menyampaikan kegunaan reusable bag bagi masyarakat secara umum (misalnya: dapat mengurangi penggunaan tas plastik yang bisa mencemari sumber daya alam yaitu tanah, bersifat ramah lingkungan karena dibuat dari bahan baku hasil daur ulang/yang tidak mengandung zat kimia) untuk meningkatkan sikap positif konsumen.

Terakhir yang tidak kalah penting adalah hasil penelitian ini juga dapat memberi sumbangan ide bagi pemerintah (Kementerian Lingkungan Hidup dan Kehutanan) untuk kembali menggalakkan pengurangan kantong plastik dengan mengampanyekan reusable bag. Peran pemerintah amat penting terutama unsur pemerintah adalah bagian dari subjective norm yang terbukti mempengaruhi sikap konsumen agar membeli reusable bag. Sekali lagi diperlukan kampanye nasional yang melibatkan Kementerian KLH dan APRINDO (Asosiasi Pengusaha Retail Indonesia) untuk mengedukasi konsumen agar bersedia meninggalkan kantong plastik dan beralih ke reusable bag.

Penelitian ini mempunyai beberapa kelemahan, antara lain jumlah responden yang relatif sedikit serta tidak dibedakan antara mereka yang belum mengetahui reusable bag dan sudah mengetahuinya. Disamping itu, penelitian ini juga tidak meneliti jenis reusable bag lain yaitu tas plastik yang diklaim bersifat mudah terurai (biodegradable) sehingga tidak mencemari tanah dan 
biasanya diberikan langsung oleh kasir saat konsumen membayar. Penelitian ini juga tidak memasukkan peran variabel trust sebagai mediator antara perceived knowledge dan revealed information terhadap attitude seperti yang dinyatakan olehJanssen dan Hamm, (2012), Vermeir dan Verbeke (2006), Zakowska-Biemans (2011) tentang pentingnya faktor trust dalam membangun sikap positif. Selain itu, penelitian ini juga menggunakan Theory-of-Reasoned Action untuk memahami intensi berperilaku yang sebenarnya teori ini telah dikembangkan lagi menjadi Theory of Planned Behavior oleh Ajzen (1991) dengan memasukkan variabel perceived behavioral control untuk lebih tepat memprediksi behavioral intention .

Untuk peneliti selanjutnya, hendaknya memperbesar jumlah sampel serta melakukan uji beda antara konsumen yang sudah/belum mengetahui manfaat reusable bag sehingga bisa diketahui bagaimana cara yang tepat untuk mengampanyekan reusable bag kepada dua kelompok tersebut. Akan menarik jika peneliti berikutnya melakukan perbandingan sikap dan intensi konsumen terkait dua jenis reusable bag, yaitu yang terbuat dari plastik mudah terurai (biodegradable) dan yang terbuat dari kain/bahan daur ulang. Perbedaan dua jenis reusable bag tersebut adalah tas plastik biodegradable sudah digunakan untuk menempatkan barang belanjaan dan gratis karena langsung diberikan oleh kasir, sedangkan reusable bag dari kain harus dibeli.

Untuk menambah kontribusi teoritis, peneliti yang akan datang juga sebaiknya mengembangkan model penelitian dengan memasukkan variabel trust sebagai mediator yang menghubungkan variabel revealed information dan perceived knowledge terhadap attitude.Penggunaan Theoryof-Planned Behavior dengan memasukkan variabel Perceived Behavioral Control juga bisa diterapkan untuk meneliti lebih lanjut bagaimana sikap dan intensi membeli konsumen terkait reusable bag, suatu perilaku peduli lingkungan yang relatif masih baru sehingga perlu dikampanyekan.

\section{Daftar Pustaka}

Ajzen, Icek. (1991). From Intentiosn to Actions: A Theory of Planned Behavior. Downloaded from www.d.umn.edu/lib/copyright.

, The Theory of Planned Behavior. (1991). Organizational and Human Decision Process, 50, p. $179-211$.

Andreassen Alan R. (1995). Social Marketing: Its Definition and Domain. Journal of PublicPolicy \& Marketing, Vol.13 (1), p. 108-114.

, (2002). Marketing Social Marketing in the Social Change Marketplace. Journal of Public Policy \& Marketing, Vol 21(1), p. 3-13.

,(2003).The Life Trajectory of Social Marketing Some Implications.Marketing Theory Vol 3 (3), p.293-303.

Bartels, J. and Reinders, M. (2010). Social identification, social representations, and consumerinnovativeness in organic food context, Food Quality and Preference, Vol. 21 No. 4, pp. 347-352.

Chang, Y.P. and Zhu, D.H. (2007). Factors influencing consumers' intention of online-shopping:an empirical study from the angle of consumer innovativeness, China Journal ofManagement, Vol. 4 No. 6, pp. 820-523.

Chen, M.F. (2007). Consumer attitudes and purchase intention in relation to organic foods in Taiwan: moderating effects of food-related personality traits, Food Quality andPreference, Vol. 18, No. 7, pp. 1008-1021.

Chen, W.P. (2011). An empirical study on the relationship among consumer lifestyle, consumer innovativeness and new product buying behavior, Economic Management, Vol. 33 No. 2, pp. 94-101. 
Chih-Ching Teng and Yu Mei-Wang. (2015). Decisional Factors Driving Organic Food Consumption. British Food Journa/Vol.117 Iss 3.pp 1066-1081

Dean, M., Raats, M.M. and Shepherd, R. (2008). Moral concerns and consumer choice for freshand processed organic foods, Journal of Applied Social Psychology, Vol. 38 No. 8, pp. 2088-2107.

Garbarino, E. and Johnson, M.S. (1999). The different roles of satisfaction, trust, and commitment in customer relationships, Journal of Marketing, Vol. 63 No. 2, pp. 70-87.

Gifford, K. and Bernard, J.C. (2006). Influencing consumer purchase likelihood of organic food, International Journal of Consumer Studies, Vol. 30 No. 2, pp. 155-163.

Gracia, A. and Magistris, T.D. (2008). The demand for organic foods in the south of Italy: adiscrete choice model, Food Policy, Vol. 33 No. 5, pp. 386-396.

Hair, Joseph. et al. (2006). Multivariate Data Analysis.Sixth Edition.Pearson International Edition.

Her Majesty's Government. (2005). Securing the Future. Vol. 6467, cm. 6467, available at: www.sustainable-development.gov.uk/publications/uk-strategy/index.htm

Honkanen, P., Verplanken, B. and Olsen, S.O. (2006). Ethical values and motives driving organicfood choice, Journal of Consumer Behaviour, Vol. 5 No. 5, pp. 420-430.

Hughner, R.S., McDonagh, P., Prothero, A., Shultz, C.J. II and Stanton, J. (2007). Who are organicfood consumers? A complication and review of why people purchase organic food, Journal of Consumer Behaviour, Vol. 6 Nos 2-3, pp. 94-110.

Im, S., Bayues, B. and Mason, C. (2003). An empirical study of consumer innovativeness, personalcharacteristics, and new-product adoption behavior, Academy of Marketing Science, Vol. 31 No. 1, pp. 61-73.

Janssen, M. and Hamm, U. (2012). Product labelling in the market for organic food: consumerpreferences and willingness-to-pay for different organic certification logos, Food Qualityand Preference, Vol. 25 No. 1, pp. 9-22.

Jones, Peter, et.al. (2008). Marketing and Sustainability. Marketing Intelligence and Planning, Vol. 26, No. n2, pp.123-130.

Kalafatis, S. and Pollard, M. (1999). Green marketing and Adjen's theory of planned behavior: across-market examination, Journal of Consumer Marketing, Vol. 16 No. 5, pp. 441-460.

Kim, D.J., Ferrin, D.L and Rao, H.R. (2008). A trust-based consumer decision making model in electronic commerce: the role of trust, perceived risk and, and their antecedenst, Decision Making Systems, Vol. 44, No. 2, pp. 544-564.

Kim, H. and Chung, J. (2011). Consumer purchase intention for organic personal care product, Journal of Consumer Marketing, Vol. 28 No. 1, pp. 40-47.

Kotler, Philip and Levy, Sidney. (1969). Broadening the Concept of Marketing. Journal ofMarketing, vol. 33, No. 1, p. 1-15.

Kotler, Philip and Zaltman, Gerard. (1971). An Approach to Planned Social Change. Journal of Marketing (35), p. 3-12.

Lao, Kefu (2014), Research on mechanism of consumer innovativeness influencing green consumption behavior, Nankai Business Review, Vol. 5 No. 2, pp 211-224.

Lassar, W., Manolis, C. and Lassar, S. (2005). The relationship between consumer innovativeness, personal characteristics, and online banking adoption, International Journal of BankingMarketing, Vol. 23 No. 2, pp. 176-199. 
Lao, Kefu. (2014). Research on mechanism of consumer innovativeness influencing green consumption behavior. Nankai Business Review International, Vol. 5, No. 2, pp. 211-224.

Luo, C. (2010). Influencing factors analysis of consumers' willingness to pay for safe food, China Rural Survey, No. 6, pp. 22-34.

Magistris, T.D. and Gracia, A. (2008). The decision to buy organic food products in SouthernItaly, British Food Journal, Vol. 110 No. 9, pp. 929-947.

Magnusson, M.K., Arvola, A., Hursti, U.K.K., Aberg, L. and Sjoden, P.O. (2003). Choice of organicfood is related to perceived consequences for human health and to environmentallyfriendly behavior, Appetite, Vol. 40 No. 2, pp. 109-117.

Morgan, R.M. and Hunt, S.D. (1994). The commitment-trust theory of relationship marketing, Journal of Marketing, Vol. 58 No. 3, pp. 20-38.

O'Fallon, M.J., Gursoy, D. and Swanger, N. (2007). To buy or not to buy: impact of labelling onpurchasing intentions of genetically modified foods, International Journal of Hospitality Management, Vol. 26 No. 1, pp. 117-130.

Padel, S. and Foster, C. (2005). Exploring the gap between attitudes and behavior understandingwhy consumers buy or do not buy organic food, British Food Journal,Vol. 107 No. 8, pp. 606-625.

Joohjung, Park and Ha Sejin. (2012). Understanding pro-environmental behavior: A comparison of sustainable consumers and apathetic consumers. International Journal of Retail and Distribution Management, Vol 40, Iss 5, p. 388-403.

Peattie, K. (2001). Golden goose or wild goose? The hunt for the green consumer.Business Strategy and the Environment, Vol. 10, No. 4, p. 187-199.

, and Crane, A. (2005). Green Marketing: legend, myth farce or prophecy? Qualitative Market Research, Vol. 8, No. 4, p. 357-370.

, and Peattie, Sue. (2008). Social Marketing: a Pathway to Consumption Reduction? Journal of Business Research, xx, p. 1-9.

Peattie, Sue and Peattie, K. (2003). Ready to fly solo? Reducing Social Marketing's Dependence on Commercial Marketing Theory. Marketing Theory, 3(3), p. 363-385.

Schaefer, Anne and Crane, Andrew. (2005). Addressing Sustainable Consumption. Journal of Macromarketing, Vol. 25, No. 1, pp. 76-92.

Schiffman, Leon G and Leslie Lazar Kanuk. (2009). Consumer Behavior Prentice Hall, Inc.

Vermeir, I. and Verbeke, W. (2006). Sustainable food consumption: exploring the consumer'attitude-behavioural intention' gap, Journal of Agricultural and Environmental Ethics, Vol. 19 No. 2, pp. 169-194.

Wu, I.L. and Chen, J.L. (2005). An extension of trust and TAM model with TPB in the initialadoption of on-line tax: an empirical study, International Journal of HumanComputerStudies, Vol. 62 No. 6, pp. 784-808.

Zakowska-Biemans, S. (2011). Polish consumer food choices and beliefs about organic food, British Food Journal, Vol. 113 No. 1, pp. 122-137.

http://www.hks.harvard.edu. 